\title{
OPEN Enriching laying hens eggs by feeding diets with different fatty acid composition and antioxidants
}

\begin{abstract}
Petru Alexandru Vlaicu ${ }^{1,2}$, Tatiana Dumitra Panaite ${ }^{1,2}$ \& Raluca Paula Turcu ${ }^{1,2}$
The current study was conducted to evaluate egg quality, egg yolk fatty acids, health-related indices and antioxidants from laying hens' eggs fed different combined vegetable by-products, rich in fatty acids and antioxidants. One hundred twenty 50 weeks-old Tetra SL laying hens were divided into three groups. They were given daily a standard diet (Control, C), a diet containing $9 \%$ rapeseed meal with 3\% grapeseed meal (T1 diet), or a diet containing $9 \%$ flaxseed meal and $3 \%$ sea buckthorn meal (T2 diet). Hen production performances, egg quality, egg yolk fatty acids total polyphenols content and antioxidant capacity were determined. The T1 diet significantly reduced the egg yolk content of palmitic acid from $76.615 \mathrm{mg}$ (C) to $46.843 \mathrm{mg}$ (T1) and that of oleic acid from $788.13 \mathrm{mg}$ (C) to $682.83 \mathrm{mg}$ (T1). Feeding flaxseed and sea buckthorn meals significantly increased the egg yolk content of $\alpha$-linolenic acid in T2 yolks ( $35.297 \mathrm{mg})$ compared with $C$ yolks $(4.752 \mathrm{mg})$ and that of docosahexaenoic acid (DHA) from $16.282 \mathrm{mg}$ (C) to $74.918 \mathrm{mg}$ (T2). The atherogenicity indices (AI) were not significantly affected, whereas the thrombogenicity indices (TI) decreased significantly $(p<0.0007)$ from 0.72 (C) to 0.60 (T1) and 0.66 (T2), respectively. Adding this combination of meals to the hens' diets, increased the total polyphenol content and antioxidant capacity in T1 and T2 eggs compared to $C$ eggs. The significant enrichment of eggs with $n-3$ fatty acids and antioxidant capacity, as well on the health-related indices especially from $\mathrm{T} 2$ eggs, represents a potential functional feed ingredient in poultry feeding, to obtain eggs as functional food.
\end{abstract}

Chicken eggs for human consumption are exceedingly nutritious, palatable, reasonable priced, and commonly accessible around the world. There is an increasing demand for enriched and functional foods for human consumption that provide various beneficial effects in addition to the nutritive and non-nutritive compounds important to human health ${ }^{1}$. Eggs can be enriched with certain nutrients through dietary manipulation to create specialty or functional food products that provide health benefits for humans ${ }^{2,3}$. Due to the benefits associated with the consumption of n-3 fatty acids (FA), many researchers have conducted studies in the last decades to enrich different foods of animal origin, such as broiler meat or eggs, in FA while delaying the lipid oxidation. The role of essential FA (linoleic and $\alpha$-linolenic) and their long-chain (LC) n- 6 and n-3 polyunsaturated fatty acids (PUFA) metabolites in human health, growth, and development is a topic of continued interest ${ }^{4,5}$. Among many important healthy beneficial effects, such as decreasing risk of cardiovascular disease, prevention and treatment of inflammatory diseases are some of the attributed given by the consumption of n-3 PUFA enriched eggs ${ }^{6}$. This type of eggs can be obtained from laying hens that are fed with different by-products rich in PUFA, like flaxseed, rapeseed, microalgae, canola, chia (seed, meals or oils), or full fat mixtures ${ }^{2,7}$. Previous studies concluded that the FA composition of eggs is dependent on the FA composition of the feed given to the hens ${ }^{8}$ which are subsequent transferred into the eggs. Fatty acids and antioxidants in eggs are essential components from a wellbeing and consumption perspective for humans, especially in terms of $\mathrm{n}-3$ PUFA consumption ${ }^{9}$. Consequently, higher fat content incorporated into laying hens' diet through rapeseed (Brassica rappa) and flaxseed (Linum usitatissimum) meal by-products is a good alternative for PUFA eggs enrichment. However, this enrichment leads to an increment within the unsaturation of eggs, and increase the susceptibility to lipid oxidation ${ }^{10}$, or give unpleasant organoleptic characteristics (fishy smell) when used in higher doses. Lipid oxidation in foods is of major significance since it antagonistically influences the general quality of foods, and nutritional value ${ }^{11}$. In order to avoid such undesirable effects, a normal way is to extend the intrinsic antioxidant concentration through dietary incorporation of natural antioxidant, such as grape seed (Vitis Vinifera) or sea buckthorn (Hippophae rhamnoides) meals. Grape is one of the world's largest fruit crops ${ }^{6}$. Grape seed is a natural agricultural by-product of grapes,

${ }^{1}$ Department of Chemistry and Animal Nutrition Physiology, National Research and Development Institute for Animal Biology and Nutrition, Balotesti, Romania. ${ }^{2}$ These authors contributed equally: Petru Alexandru Vlaicu, Tatiana Dumitra Panaite and Raluca Paula Turcu. ${ }^{\circledR}$ email: alexandru.vlaicu@outlook.com 


\begin{tabular}{|c|c|c|c|c|c|}
\hline Items & $\mathrm{C}$ & T1 & T2 & SEM & $\mathbf{p}$ \\
\hline \multicolumn{6}{|l|}{\begin{tabular}{|l|} 
Laying performances \\
\end{tabular}} \\
\hline Average daily feed intake (g/day/hen) & 118.19 & 118.99 & 119.31 & 0.554 & 0.1741 \\
\hline Feed conversion ratio (kg CF/kg egg) & 2.08 & 2.06 & 2.05 & 0.711 & 0.4340 \\
\hline Laying rate (\%) & 89.30 & 90.56 & 90.26 & 0.021 & 0.0787 \\
\hline \multicolumn{6}{|l|}{ Egg quality characteristics } \\
\hline Egg weight $(\mathrm{g})$ & 63.50 & 63.53 & 63.72 & 0.156 & 0.8261 \\
\hline Albumen $(\mathrm{g})$ & 37.86 & 38.29 & 37.95 & 0.226 & 0.7271 \\
\hline Yolk (g) & 17.00 & 16.71 & 16.86 & 0.201 & 0.6251 \\
\hline Shell (g) & 8.64 & 8.71 & 8.91 & 0.115 & 0.6217 \\
\hline Shell thickness $(\mu \mathrm{m})$ & 350.0 & 350.0 & 360.1 & 0.003 & 0.5754 \\
\hline Shell strength (kgF) & 3.77 & 4.00 & 3.66 & 0.111 & 0.4515 \\
\hline Albumen pH & $8.95^{\mathrm{a}}$ & $8.84^{\mathrm{ab}}$ & $8.71^{\mathrm{b}}$ & 0.036 & 0.0245 \\
\hline Yolk pH & $6.23^{\mathrm{a}}$ & $6.21^{\mathrm{b}}$ & $6.20^{\mathrm{b}}$ & 0.012 & 0.0004 \\
\hline Yolk colour fan & $4.67^{\mathrm{c}}$ & $5.06^{\mathrm{b}}$ & $6.78^{\mathrm{a}}$ & 0.082 & 0.0055 \\
\hline Haugh units (HU) & 82.12 & 85.82 & 85.97 & 1.092 & 0.6169 \\
\hline
\end{tabular}

Table 1. Effect of dietary by-products on laying performances and egg quality characteristics. $C$ control diet, T1 control diet with $9 \%$ rapeseed meal and 3\% grapeseed meal, T2 control diet with $9 \%$ flax meal and 3\% buckthorn meal, SEM standard error of the mean, $p$ significance. ${ }^{\text {abc }}$ Mean marked with a different superscript letter within each column are significantly different.

considered a natural source of anti-oxidative constituents (vitamin E, flavonoids, pro-anthocyanidins and polyphenols $)^{12}$. Sea buckthorn is widely distributed all over the world. It contains different nutrients and bioactive substances such as vitamins, carotenoids, flavonoids, polyphenols and PUFA ${ }^{13}$. Both grapeseed and sea buckthorn meal are underexploited by-products, which have gain attention in the last years, as natural antioxidant sources with biological benefits. Dietary supplementation with natural antioxidant sources has been demonstrated to be very successful in improving poultry products in antioxidants and concomitant delay the lipid oxidation of products which could be produced by the high fat content of the egg ${ }^{14}$.

To our knowledge, there are little studies performed following similar dietary inclusion. Thus, the objective of the present study was to evaluate the effect of the dietary incorporation of rapeseed and flaxseed meals as different natural sources of polyunsaturated fatty acids together with a natural source of antioxidant, namely grapeseed meal and sea buckthorn meal on laying hens' performances, egg yolk fatty acids, health-related indices, total polyphenol content and antioxidant capacity of eggs.

\section{Results}

Laying hens performances and egg physical quality characteristics. The usage of T1 and T2 diets had no effect ( $p>0.05)$ on laying hens' performances (Table 1$)$. It was observed only a tendency of increasing the average daily feed intake and a decrease of feed conversion ratio in T2 group. Egg weight and laying rate were higher in experimental treatments, but without a notable $(p>0.05)$ effect. Overall, the diets used were not significant $(\mathrm{p}>0.05)$ contributors in relationship to the obtained performances. The tested diets did not influence the egg weight or egg constituents (albumen, yolk and shell) (Table 1). However, egg albumen pH was significantly lower $(\mathrm{p}=0.0245)$ in T2 compared with $\mathrm{C}$, while the egg yolk $\mathrm{pH}$ was significantly lower $(\mathrm{p}=0.0004)$ in both T1 and T2 compared with C samples. The yolk colour from T1 and T2 groups, measured with a Roche colour fan, was significantly $(p=0.0155)$ improved compared with $C$ samples. Haugh unit $(H U)$, parameter was $4.31 \%$ higher in $\mathrm{T} 1$ and $4.47 \%$ higher in $\mathrm{T} 2$ compared with $\mathrm{C}$ eggs.

Fatty acid composition of the analysed eggs. The effect of using diets rich in PUFA and antioxidants on the FA composition of egg yolk is shown in Table 2. Among the SFA, the most abundant were myristic $(\mathrm{C} 14: 0)$, which has been significantly $(\mathrm{p}<0.0051)$ higher in $\mathrm{C}$ compared with $\mathrm{T} 1$ and $\mathrm{T} 2$. Additionally, palmitic acid $(\mathrm{C} 16: 0)$ was significantly $(\mathrm{p}<0.0001)$ higher in $\mathrm{C}$ and $\mathrm{T} 2$ compared with $\mathrm{T} 1$ egg yolks, followed by stearic (C18:0) which had the tendency to be higher in T2 compared with C and T1. Heptadecanoic acid (C17:0) was significantly $(\mathrm{p}<0.0603)$ higher only in T1 compared with $\mathrm{C}$ egg yolks. Regarding the MUFA content in egg yolk samples, palmitoleic acid $(\mathrm{C} 16: 1)$ and oleic acid $(\mathrm{C} 18: 1)$ were significantly $(\mathrm{p}<0.05)$ higher in the samples from $\mathrm{C}$ and T2 compared to T1 yolks. Nervonic acid (C24:1n9) was significantly $(\mathrm{p}<0.0001)$ higher in both $\mathrm{C}$ and T1 compared with T2 samples. Furthermore, the birds which consumed T1 diet have deposited higher $(\mathrm{p}<0.0001)$ amounts of n-6 PUFA, while the birds which consumed T2 diet have deposited higher $(\mathrm{p}<0.0001)$ amounts of n-3 PUFA, as a response of different PUFA sources added in diets. From the total essential n-6 PUFA determined in egg yolks from $\mathrm{T} 1$, linoleic acid $(\mathrm{C} 18: 2 \mathrm{n} 6)$ and arachidonic $(\mathrm{C} 20: 4 \mathrm{n} 6)$ were significantly $(\mathrm{p}<0.001)$ higher compared with C and T2. Nevertheless, out of the total essential n-3 PUFA, the most important and dominant ones involved in human physiology were identified in egg yolks from T2. The a-linolenic (C18:3n3) was almost eight times higher compared with $\mathrm{C}$ and T1 eggs. Moreover, the docosapentaenoic acid (C22:5n3) was signifi- 


\begin{tabular}{|c|c|c|c|c|c|}
\hline \multirow[b]{2}{*}{ Item } & C & T1 & T2 & SEM & $\mathbf{p}$ \\
\hline & \multicolumn{5}{|c|}{ mg fatty acids/yolk } \\
\hline Yolk Fat, \% DM & 27.24 & 27.04 & 27.06 & 0.217 & 0.9250 \\
\hline Myristic C14:0 & $7.390^{\mathrm{a}}$ & $5.505^{\mathrm{b}}$ & $5.662^{\mathrm{b}}$ & 0.281 & 0.0028 \\
\hline Pentadecanoic C15:0 & 1.518 & 1.575 & 1.693 & 0.072 & 0.6241 \\
\hline Palmitic C16:0 & $582.96^{\mathrm{a}}$ & $510.35^{\mathrm{b}}$ & $553.67^{\mathrm{a}}$ & 9.495 & 0.0015 \\
\hline Heptadecanoic C17:0 & 2.603 & 3.428 & 2.767 & 0.170 & 0.1040 \\
\hline Stearic C18:0 & 247.20 & 268.57 & 239.50 & 7.495 & 0.2742 \\
\hline$\sum$ SFA & 841.68 & 789.43 & 803.28 & 12.628 & 0.2254 \\
\hline Pentadecenoic C15:1 & 2.598 & 2.802 & 2.703 & 0.154 & 0.8790 \\
\hline Palmitoleic C16:1 & $76.615^{\mathrm{a}}$ & $46.843^{\mathrm{b}}$ & $76.402^{\mathrm{a}}$ & 3.990 & 0.0005 \\
\hline Heptadecenoic C17:1 & 1.925 & 2.512 & 2.268 & 0.150 & 0.2990 \\
\hline Oleic C18:1 & $788.13^{\mathrm{a}}$ & $682.83^{b}$ & $778.99^{\mathrm{a}}$ & 17.838 & 0.0170 \\
\hline Erucic C22:1n9 & 2.536 & 3.068 & 2.086 & 0.255 & 0.2979 \\
\hline Nervonic C24:1n9 & $8.512^{\mathrm{a}}$ & $8.653^{\mathrm{a}}$ & $3.935^{\mathrm{b}}$ & 0.594 & $<0.0001$ \\
\hline$\Sigma$ MUFA & $876.79^{a}$ & $746.69^{\mathrm{b}}$ & $867.67^{\mathrm{a}}$ & 21.028 & 0.0088 \\
\hline Linoleic C18:2n6 & $425.18^{\mathrm{a}}$ & $501.70^{\mathrm{b}}$ & $369.86^{\mathrm{c}}$ & 16.651 & 0.0007 \\
\hline Linolenic $\gamma$ C18:3n6 & $2.912^{\mathrm{a}}$ & $2.340^{\mathrm{b}}$ & $2.014^{\mathrm{b}}$ & 0.132 & 0.0061 \\
\hline Eicosadienoic C20:2n6 & 3.542 & 4.175 & 2.888 & 0.309 & 0.2274 \\
\hline Eicosatrienoic C20:3n6 & $6.274^{\mathrm{b}}$ & $7.802^{\mathrm{a}}$ & $4.678^{\mathrm{c}}$ & 0.402 & 0.0005 \\
\hline Arachidonic C20:4n6 & $94.422^{\mathrm{a}}$ & $105.238^{\mathrm{a}}$ & $3.40^{\mathrm{b}}$ & 0.168 & 0.0005 \\
\hline Docosatetraenoic C22:4n6 & $37.29^{\mathrm{a}}$ & $35.432^{\mathrm{a}}$ & $5.742^{\mathrm{b}}$ & 3.640 & $<0.0001$ \\
\hline a-Linolenic C18:3n3 & $4.752^{\mathrm{b}}$ & $4.355^{\mathrm{b}}$ & $35.297^{\mathrm{a}}$ & 3.571 & $<0.0001$ \\
\hline Eicosatrienoic C20:3n3 & 5.315 & 5.508 & 6.408 & 0.347 & 0.4137 \\
\hline Docosapentaenoic C22:5n3 & $1.755^{\mathrm{b}}$ & $1.498^{\mathrm{b}}$ & $5.60^{\mathrm{a}}$ & 0.486 & $<0.0001$ \\
\hline Docosahexaenoic C22:6n3 & $16.282^{\mathrm{b}}$ & $16.352^{\mathrm{b}}$ & $74.918^{\mathrm{a}}$ & 6.766 & $<0.0001$ \\
\hline ¿PUFA & $596.55^{\mathrm{b}}$ & $682.72^{\mathrm{a}}$ & $584.25^{\mathrm{b}}$ & 16.757 & 0.0211 \\
\hline n-3 PUFA & $28.103^{\mathrm{b}}$ & $27.713^{\mathrm{b}}$ & $122.23^{\mathrm{a}}$ & 10.877 & $<0.0001$ \\
\hline n-6 PUFA & $568.45^{\mathrm{b}}$ & $655.05^{\mathrm{a}}$ & $462.03^{\mathrm{c}}$ & 22.596 & $<0.0001$ \\
\hline$n-6 / n-3$ & $471.39^{\mathrm{a}}$ & $528.25^{\mathrm{a}}$ & $85.252^{\mathrm{b}}$ & 48.881 & $<0.0001$ \\
\hline$\sum U F A$ & 1473.34 & 1429.41 & 1451.92 & 21.889 & 0.7582 \\
\hline
\end{tabular}

Table 2. Effect of dietary by-products on the egg yolk fatty acids profile. SFA saturated fatty acids, MUFA monounsaturated fatty acids, PUFA polyunsaturated fatty acids, $n-6$ omega 6 fatty acids, $n-3$ omega 3 fatty acids, UFA unsaturated fatty acids, $C$ control diet, $T 1$ control diet with $9 \%$ rapeseed meal and $3 \%$ grapeseed meal, T2 control diet with $9 \%$ flax meal and 3\% buckthorn meal, SEM standard error of the mean, $p$ significance. ${ }^{\mathrm{abc}}$ Mean marked with a different superscript letter within each column are significantly different.

cantly $(\mathrm{p}<0.0001)$ higher, while the docosahexaenoic acid $(\mathrm{C} 22: 6 \mathrm{n} 3)$ was almost five times higher compared to the concentrations determined in $\mathrm{C}$ and $\mathrm{T} 1 \mathrm{egg}$ yolks, as a response of flax meal added in this diet.

Health-related lipid indices. The obtained health indices calculated in the present study are outlined in Table 3. Saturation indices (SI) and atherogenic indices (AI) were higher in C eggs, but without significant $(\mathrm{p}>0.05)$ alteration in contrast with T1 and T2. The thrombogenicity indices (TI) were significantly $(\mathrm{p}=0.0007)$ different among all egg samples. As expected, the peroxidability indices (PI) was significantly $(\mathrm{p}<0.0001)$ higher, in T1 and T2 vs. C group. The values of oxidative susceptibility (OS), desirable fatty acids (DFA), nutritive value (NVI) and ratio between hypocholesterolemic and hypercholesterolemic (HH) health indices from T1 and T2 egg samples, presented significantly $(\mathrm{p}<0.0001)$ higher values than in $\mathrm{C}$ eggs. In term of hypercholesterolemic saturated fatty acids (HFSA), egg samples from C group had the highest $(\mathrm{p}<0.0001)$ value $(25.50)$, followed by T2 (24.80) and T1 (23.29). On the other hand, C egg samples had the lowest oxidisability value (Cox) $(p=0.0001)$.

Antioxidant compounds of the eggs. In the Table 4 are presented the effects of dietary by-products added in laying hens' diets on total polyphenol content (TPC) and total antioxidant capacity (TAC) determined in eggs. The T2 group, which was supplemented with flaxseed and sea buckthorn meals, had significantly $(\mathrm{p}<0.001)$ increased the TPC compared with C. Similarly, the TPC determined in eggs from T1, supplemented with rapeseed and grapeseed meals, led to an increase of $4.03 \%$ higher than $C$, but without statistical $(\mathrm{p}>0.05)$ differences. The eggs from T2 were also constant in terms of TAC determined in both yolk and albumen egg. The methanolic egg yolk and albumen extracts exhibited statistically significant differences in TAC, as measured using the DPPH method. The highest concentration was observed in both yolk (80.28 $\mathrm{mM}$ Trolox/g) and albumen ( $86.15 \mathrm{mM}$ Trolox/g) extract from T2 eggs, followed by the extract from T1 egg (respectively 


\begin{tabular}{|l|r|r|r|l|l|}
\hline Items & \multicolumn{1}{l|l}{ C } & \multicolumn{1}{l|}{ T1 } & \multicolumn{1}{l|}{ T2 } & \multicolumn{1}{l|}{ SEM } & \multicolumn{1}{l|}{ p } \\
\hline Saturation indices (SI) & 0.57 & 0.55 & 0.55 & 0.007 & 0.4631 \\
\hline Atherogenicity indices (AI) & 0.58 & 0.56 & 0.56 & 0.007 & 0.3552 \\
\hline Thrombogenicity indices (TI) & $0.72^{\mathrm{a}}$ & $0.60^{\mathrm{c}}$ & $0.66^{\mathrm{b}}$ & 0.015 & 0.0007 \\
\hline Peroxidability indices (PI) & $27.37^{\mathrm{c}}$ & $30.91^{\mathrm{b}}$ & $44.92^{\mathrm{a}}$ & 1.919 & $<0.0001$ \\
\hline Hypo/hypercholesterolemic (HH) & $0.81^{\mathrm{c}}$ & $1.18^{\mathrm{a}}$ & $0.94^{\mathrm{b}}$ & 0.038 & $<0.0001$ \\
\hline Hypercholesterolemic saturated fatty acids (HSFA) & $25.50^{\mathrm{a}}$ & $23.29^{\mathrm{b}}$ & $24.80^{\mathrm{a}}$ & 0.267 & $<0.0001$ \\
\hline Oxidisability value (Cox) & $2.30^{\mathrm{b}}$ & $2.70^{\mathrm{a}}$ & $2.39^{\mathrm{b}}$ & 0.048 & 0.0001 \\
\hline Oxidative susceptibility (OS) & $897.70^{\mathrm{c}}$ & $1075.56^{\mathrm{a}}$ & $979.60^{\mathrm{b}}$ & 3.036 & 0.0001 \\
\hline Desirable fatty acids (DFA) & $74.11^{\mathrm{b}}$ & $75.98^{\mathrm{a}}$ & $76.47^{\mathrm{a}}$ & 0.263 & 0.0001 \\
\hline Nutritive value indices (NVI) & $1.77^{\mathrm{b}}$ & $1.86^{\mathrm{a}}$ & $1.84^{\mathrm{ab}}$ & 0.018 & 0.0088 \\
\hline
\end{tabular}

Table 3. Effect of dietary by-products on health-related lipid indices of egg yolks. $C$ control diet, $T 1$ diet supplemented with $9 \%$ rapeseed meal with $3 \%$ grapeseed meal, $T 2$ diet supplemented with $9 \%$ flaxseed meal with $3 \%$ sea-buckthorn meal, SEM standard error of the mean, $p$ significance. ${ }^{a b c}$ Mean marked with a different superscript letter within each column are significantly different.

\begin{tabular}{|l|l|l|l|l|l|}
\hline Items & C & T1 & T2 & \multicolumn{1}{l|}{ SEM } & p \\
\hline Total polyphenol concentration (TPC) (mg GAE/g egg) & $40.94^{\mathrm{b}}$ & $43.66^{\mathrm{a}}$ & $45.36^{\mathrm{a}}$ & 17.385 & 0.0075 \\
\hline Total antioxidant capacity TAC) (mM Trolox/g yolk) & $75.34^{\mathrm{b}}$ & $79.56^{\mathrm{a}}$ & $80.28^{\mathrm{a}}$ & 1.130 & 0.0015 \\
\hline Total antioxidant capacity (TAC) (mM Trolox/g albumen) & $80.47^{\mathrm{b}}$ & $85.30^{\mathrm{a}}$ & $86.15^{\mathrm{a}}$ & 0.946 & 0.0094 \\
\hline
\end{tabular}

Table 4. Effect of dietary by-products on antioxidant compounds determined in eggs. $C$ control diet, $T 1$ control diet with $9 \%$ rapeseed meal and 3\% grapeseed meal, $T 2$ control diet with $9 \%$ flaxseed meal and $3 \%$ sea buckthorn meal, SEM standard error of the mean, $p$ significance. ${ }^{\text {ab }}$ Mean marked with a different superscript letter within each column are significantly different.

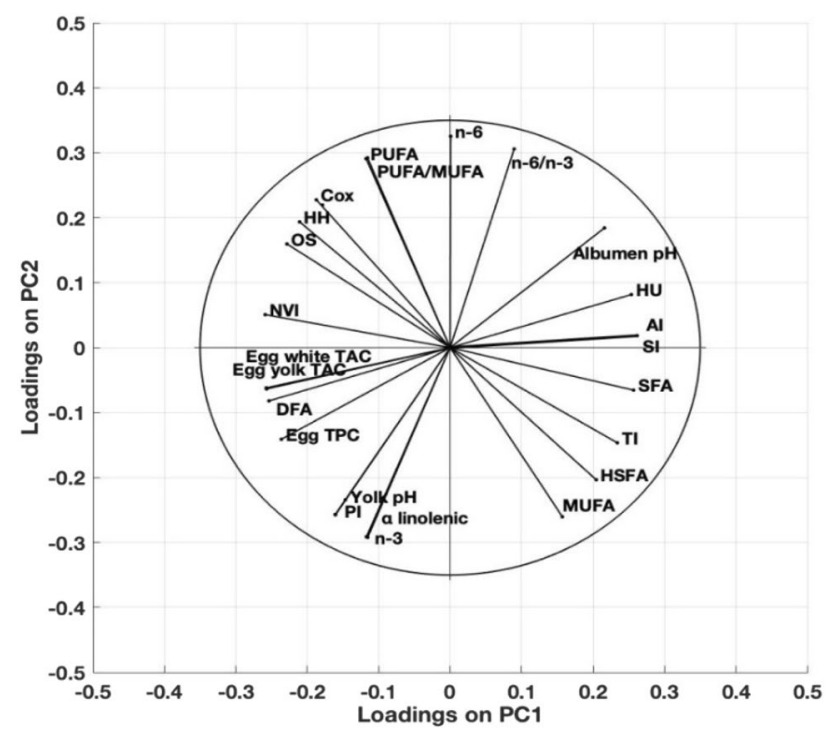

Figure 1. Principal component analysis and correlation loading of fatty acids, health indices, total phenolic compounds, antioxidant capacity, HU, yolk and albumen $\mathrm{pH}$ of the analysed egg samples.

$79.56 \mathrm{mM}$ Trolox/g and $85.30 \mathrm{mM}$ Trolox/g), which resulted being significantly $(\mathrm{p}<0.001)$ higher compared with C egg yolk (75.34 mM Trolox/g) and egg albumen (80.47 mM Trolox/g).

The relationship between egg characteristics given by principal components analysis (PCA). To verify which parameters were more related with the detected differences, the PCA was applied to all determined egg quality parameters (Fig. 1). PCA is one of multivariate statistical methods used for exploratory data analysis to uncover hidden relationships between various parameters taken at once. The loadings of the original variables on the first two principal components, was described by $75 \%$ of the total variance for PC1 
and by $20 \%$ for PC2. Our data showed that there is a positive correlation between health indices and antioxidant compounds, while the antioxidant compounds are negatively correlated. On the other hand, it was found a strong correlation between the antioxidant compounds and fatty acids classes, as expected.

\section{Discussion}

Our dietary treatments were without significant effect on hens' performances. The results reported in literature on the effect of these by-products (rapeseed meal, grapeseed meal, flaxseed meal or sea buckthorn meals) on laying hens used alone or together with different supplements on performances are controversial ${ }^{15-17}$. Various factors have been reported to have the ability to influence differently the performances ${ }^{18}$, including the duration of these trials or the inclusion level of this by-products. In this study, egg weight or egg constituents (shell, yolk or albumen) were not influenced by the experimental diets. In line with our findings ${ }^{18}$ similar results were obtained in terms of egg constituents when hens were subjected to diets rich in PUFA from flaxseed, rapeseed or fish oil. Lower $\mathrm{pH}$ values in egg albumen and yolk are a wanted effect, which means that the natural antioxidants added in the diets acted against lipid oxidation products in eggs. The increased egg yolk colour from T1 and $\mathrm{T} 2$ groups is also a beneficial result considering that yolk colour has always been regarded as an important egg quality characteristic and as a key criterion to producers and consumers who are attracted by well-pigmented egg products. Actually, consumers tend to associate golden yellow to orange yolk with good health ${ }^{19}$. Similarly, Momani et al. ${ }^{20}$ reported that $5 \%$ sea buckthorn meal had significant effect on egg yolk colour, which supports our results obtained from T2 egg yolk colour.

Manipulating laying hens' diets by adding different by-products rich in fatty acids and antioxidant resulted in significant changes in the FA profile of eggs. Compared with eggs from group C, the lowest total SFA values were determined in eggs produced from hens fed with experimental diets (T1 and T2). Palmitic acid (C16:0) was the most abundant SFA in eggs from C group (582.96 mg FA/yolk), followed by eggs from T2 (553.67 mg $\mathrm{FA} /$ yolk) which is known to be the primary product of FA synthetase reactions within the tissues ${ }^{21}$. Once it is released from the synthetase complex, it can be esterified into complex lipids, which are further elongated to de novo stearic acid (C18:0) or desaturated to the MUFA, palmitoleic acid (C16:1), involving different enzymatic pathways in each reaction ${ }^{22}$. The effect of significant increase in palmitoleic (C16:1) and oleic (C18:1) from C and T2 eggs compared to T1 yolks, led to a significant increase in total MUFA from C (876.79 mg FA/yolk) and T2 (867.67 mg FA/yolk) eggs when compared with T1 eggs (746.69 mg FA/yolk). These results were unexpected taking into consideration the fact that $\mathrm{C}$ and $\mathrm{T} 1$ diets had higher concentration of MUFA compared with T2. This effect has been also con-firmed by other authors ${ }^{4,23}$ and it happens due to the fact that FA synthesis in animal systems produce only SFA and MUFA of the n-9 series, usually oleic acid (C18:1). Furthermore, birds that consumed T1 diet deposited higher $(\mathrm{p}<0.0001)$ amounts of $\mathrm{n}-6$ PUFA, especially linoleic $(\mathrm{C} 18: 2 \mathrm{n} 6)$ and arachidonic acids (C20:4n6) compared with concentrations determined in C and T2. This increase in T1 eggs is related to the rapeseed meal and grapeseed meal, both having higher concentrations of $n-6$ compared with by-products used in T2. Similarly, Halle and Schöne ${ }^{24}$, measured high concentration of linoleic acid determined in yolk lipids, caused by addition of $10 \%$ rapeseed cake, which is very close to our obtained result of $501.70 \mathrm{mg}$ fatty acids/ yolk linoleic acid in T1 eggs. Moreover, Rowghani ${ }^{25}$ found that by adding 3 and $5 \%$ canola oil, the percentage of total n-3 FA compared with C egg samples significantly $(p<0.05)$ increased. Nevertheless, other authors ${ }^{26,27}$ concluded that $10 \%$ rapeseed cake or different mixtures of rapeseed, flaxseed, fish oils provide the possibility of the enrichment of yolk fat with PUFA. What is more, the laying hens that consumed T2 diet deposited higher a-linolenic acid and docosahexaenoic, resulting in an increase of the total n-3 FA and a decrease in n- 6 PUFA, especially arachidonic acid when compared with eggs from C and T1. Our results are in line with previous studies on laying hens fed diets containing same by-products ${ }^{24,25}$. In addition, Imran et al. ${ }^{28}$ by using $10 \%, 20 \%$ and $30 \%$ extruded flax meal in hen's diet reported a significant improvement of $\alpha$-linolenic and docosahexaenoic acid in egg yolk with a concomitant reduction in arachidonic acid which is similar with our obtained results from T2 eggs. This is a beneficial effect considering that generally, table eggs tend to be relatively high in n-6 FA and scarce in n-3 FA, as it was previously reported ${ }^{1}$. The variation of SFA, MUFA and PUFA among the groups occurs due to the conversion of one FA into another, such as stearic acid in oleic acid, but also due to the action of the enzyme in the formation and depletion of $\mathrm{FA}^{18}$. The differences between the two experimental groups (T1 and T2), could be caused by the decreased arachidonic acid, (as in T2 eggs) which is formed from linoleic acid through desaturation and elongation in the hen liver, where $\alpha$-linolenic is metabolized to LC n-3 FA by $\Delta 6$-, $\Delta 5$-, and $\Delta 4$-desaturases and elongases ${ }^{29}$. Furthermore, the process of desaturation and elongation, leads to a competition for the enzymes between $n-3$ and n-6 FA with a preference for $n-3$ over n- 6 PUFA $^{30,31}$. It has been shown that saturated and trans fats inhibit the $\Delta 6-, \Delta 5$-pathways, limiting LC-FA concentrations, but the inclusion of antioxidants (synthetic or natural) modulates $\Delta 6$-desaturase (it is the critical enzyme in these reactions) pathway in a favourable manner and increase LC n-3 FA concentration in eggs ${ }^{30}$, for which it has a great affinity. By reporting the fatty acid profile as $\mathrm{mg} / \mathrm{egg}$ yolk, it is very clear to observe that T2 egg provide about $110.21 \mathrm{mg}$ of n-3 per egg from $\alpha$-linolenic acid and docosahexaenoic acid. This concentration supplies almost half of the daily recommended dose of this important fatty acids. With respect to the T1 eggs, they supply high amounts of n-6 and scarce amount of n-3, which is similar to eggs from C group. Hence, using diets rich in n-3 FA (as T2 diet) reduces the n-6 FA of egg yolk, which represents a favourable effect for consumers. This may prove to be a key food ingredient for obtaining functional foods and establishing egg consumption for promoting better health effects in humans.

Data obtained on egg lipid components, emphasize the strong influence of FA lipid profile in eggs from T1 and T2 on health lipid indices. The PUFA together with their ratio are the FA controlling the hypocholesterolemic indices. The n-3 PUFA plays a major role for regulating the TI, whereas n-6 PUFA are dominant for the AI. Healthy animal products (eggs, meat) are characterized by lower values of AI and TI but with high value 
of $\mathrm{HH}$ indices ${ }^{32}$. AI and TI are vital parameters for evaluating the healthiness of lipid for human consumption, indicating the potential of providing benefits for health of cardiovascular system ${ }^{33}$. The recommended levels for human consumption of AI and TI should be less than 1.0 as it was also found in other studies ${ }^{34}$. Our results showed that AI were equal in both experimental eggs (0.56) while TI were significantly lower in T1 (0.60) and T2 (0.66) compared with C (0.72). The significant decrease of total MUFA it was also reflected in the HSFA from T1 (23.29) and T2 (24.80) vs. C (25.50) eggs, which it was reported to be very effective in lowering blood cholesterol concentration and in preventing coronary heart disease in elderly people ${ }^{1}$. These results are very desirable from a human health point of view. Our results are in good agreement or close to those calculated on the basis of FA profile for laying hens by other authors ${ }^{35,36}$. On the other hand, according to an $\mathrm{FAO}^{6}$ report, PI, $\mathrm{HH}, \mathrm{OS}, \mathrm{DFA}$ and NVI should be as high as possible, considered to have eitherneutral or cholesterol-lowering effects $^{37}$. Our PI obtained values in eggs from T1 (30.91) and T2 (44.92), were higher than those from C eggs (27.37), indicating a higher pro-health value of obtained eggs. Similarly, Batkowska et al. ${ }^{38}$ showed higher PI values than control group. The significantly higher value of $\mathrm{HH}$ health indices values obtained from T1 (1.18) and T2 (0.94) egg samples, represent a beneficial effect for human health, the higher this ratio is, the more adequate that fat is for human nutrition. Similar effects have been also attributed to the oxidative susceptibility indices, which were with $16.54 \%$ higher in T1 and with $8.36 \%$ higher in T2 eggs, from hens' fed diets rich in PUFA and antioxidants. Additionally, the highest value determined for nutritive value indices (NVI) was characteristic for both T1 (1.84) and T2 (1.84) eggs compared with C (1.77) eggs. All in all, it is difficult to compare these health indices obtained in the present study from hens fed with these natural by-products. The main reason for this conclusion is the lack of re-searches and studies related to the assessment of health indices on hens' egg yolk following similar dietary incorporation.

The concentration of PUFA, which were incorporated into eggs by feeding T1 and T2 diets to laying hens might increase the susceptibility to oxidation of the FA, considering the fact that eggs, in particular those enriched in PUFA, are highly prone to oxidative processes ${ }^{39}$. It was reported that the antioxidant compounds such as polyphenols, vitamins and minerals from eggs, act synergistically with each other, providing a protective effect against eventual lipid peroxidation ${ }^{40}$, due to efficiency of nutrient transfer from the feed to the egg. For this reason, simultaneously enrichment of eggs with polyphenols and antioxidant compounds was suggested to decrease FA oxidation and provide a good source of dietary antioxidant ${ }^{8}$. The results gathered in this study indicate that the by-products added in T1 and T2 diets were effective in improving egg quality after 6 weeks of feeding by increasing the polyphenols and antioxidant capacity in eggs. Moreover, it was clear that the used by-products, exhibited high antioxidant properties by manipulation of poultry feed, which further promoted a significant enhancement in polyphenols and antioxidant compounds in laying hens' eggs of experimental group compared with control group eggs. The polyphenol concentration increased in both experimental eggs, but the significant increase was noted in T2 eggs (45.36 mg GAE/g) compared with C eggs (40.94 mg GAE/g). Also, the antioxidant capacity increased significantly in egg yolk (79.56 in T1 and 80.28 in T2 mM Trolox/g) and egg albumen (85.30 in $\mathrm{T} 1$ and $86.15 \mathrm{in} \mathrm{T} 2 \mathrm{mM}$ Trolox/g) in both experimental groups compared with C egg yolk (75.34 mM Trolox/g) and egg albumen $(80.47 \mathrm{mM}$ Trolox/g). This effect is also attributed to the major role of bioactive compounds present in the added by-products as natural source of antioxidants which are responsible for health promoting action $^{28}$. Other authors ${ }^{41,42}$ reported that high concentration of polyphenols implies that the antioxidants of the by-products significantly increase because of its capacity to block free radicals. This relationship between polyphenols and antioxidants was also reported by others ${ }^{43,44}$. In line with our results, Karakaya et al. ${ }^{45}$ reported that different levels of antioxidants from grapeseed and their by-products were significantly $(\mathrm{p}<0.05)$ effective in fresh eggs. The effectiveness of sea buckthorn was also studied previously, as natural source of bioactive compounds in laying hens ${ }^{46,47}$ on egg quality, with beneficial effects. As it has been stated before, PUFA enriched eggs simultaneously with polyphenols and antioxidant compounds help antioxidant assimilation ${ }^{48}$. This is a wanted effect from a consumer perspective, considering that some evidence from $\mathrm{WHO}^{49}$ strongly supports a contribution of polyphenols to the prevention of cancers, cardiovascular diseases, and osteoporosis and suggests a role in the prevention of neurodegenerative diseases and diabetes mellitus ${ }^{50}$. As it was shown polyphenols improve the status of different oxidative stress biomarkers ${ }^{51}$ and it is established that some polyphenols, administered as supplements or with food, do improve health status ${ }^{52,53}$ especially protective effects against cardiovascular diseases ${ }^{54}$. Overall, in the light of the findings from the present study, provide additional support that the production of eggs enriched with polyunsaturated fatty acids and antioxidant compounds, which may give poultry farmers an opportunity to be part of an emerging industry that could increase marketability by offering consumers an alternate way of obtaining these health-promoting nutrients through their diet.

The PCA analysis of bi-plot of the fatty acid classes, health indices and antioxidants were carried out because this matrix is a very complex mixture. The PCA model with two significant components, and the positive or negative relationship between them was explained by $75 \%$, of the variance in the original parameters (PC1) and by $20 \%$ for the second component (PC2), respectively. The highest positive correlation was found among the concentrations of PUFA, PUFA/MUFA ratio, n-3 and n- 6 fatty acids. The TPC from both yolk and albumen, were also strongly correlated. These results suggest that phenolic compounds, such as phenolic acids and flavonoids, may be important contributors to the antioxidant capacity. From the health-related indices AI, SI, NVI and PI had the strongest correlation. For the rest of the parameters, the correlation was moderate. We also took into consideration a-linolenic FA, as the most important one, which was strongly correlated with PI indices and n-3 FA, while for the same parameter was observed a strong negative correlation with n-6 FA. A high negative relationship was also found between SFA and PUFA. 


\begin{tabular}{|c|c|c|c|c|}
\hline Specification & Rapeseed meal & Grapeseed meal & Flaxseed meal & Sea Buckthorn meal \\
\hline \multicolumn{5}{|l|}{ Proximate analysis of nutrients (\% DM) } \\
\hline Dry matter & 89.25 & 89.91 & 90.86 & 89.36 \\
\hline Crude protein & 33.56 & 13.10 & 31.38 & 11.44 \\
\hline Ether extract & 15.07 & 6.44 & 13.14 & 8.92 \\
\hline Crude fibre & 10.10 & 35.16 & 11.26 & 23.26 \\
\hline \multicolumn{5}{|l|}{ Fatty acid content (\% of total fat) } \\
\hline Palmitic (C16:0) & 11.92 & 9.68 & 7.70 & 21.56 \\
\hline Stearic $(\mathrm{C} 18: 0)$ & 2.73 & 3.56 & 3.07 & 1.80 \\
\hline Oleic (18:1) & 41.06 & 21.04 & 18.54 & 30.70 \\
\hline Linolenic (C18:3n3) & 4.42 & 1.33 & 42.93 & 4.84 \\
\hline Total SFA & 16.83 & 13.48 & 11.07 & 23.69 \\
\hline Total MUFA & 42.90 & 21.34 & 18.71 & 45.39 \\
\hline Total PUFA & 40.26 & 64.71 & 70.23 & 30.44 \\
\hline n-6 PUFA & 35.85 & 63.23 & 27.30 & 25.40 \\
\hline n-3 PUFA & 4.42 & 1.47 & 42.93 & 5.04 \\
\hline n-6/n-3 ratio & 8.12 & 42.91 & 0.64 & 5.04 \\
\hline \multicolumn{5}{|l|}{ Antioxidant compounds } \\
\hline Polyphenols (mg GAE/g) & 7.95 & 90.42 & 15.33 & 90.72 \\
\hline Antioxidant capacity (mM Trolox/g) & 24.57 & 496.0 & 19.87 & 118.50 \\
\hline Flavonoids ( $\mu$ g rutin $/ \mathrm{g}$ ) sample $(\mu \mathrm{g} \mathrm{RE} / \mathrm{g})$ & 4.51 & 100.08 & 1.35 & 120.01 \\
\hline
\end{tabular}

Table 5. Proximate chemical composition and nutrient profile of dietary by-products. PUFA polyunsaturated fatty acids, $D M$ dry matter.

\section{Methods}

Ethical considerations. The study was approved before the initiation of research, by the Ethical Commission of the National and Development Institute for Biology and Animal Nutrition (INCDBNA-IBNA), Balotesti according to the experimental protocol no. 454/23 January 2019 and in compliance with the ARRIVE guidelines.

The study complied with the principles of Romanian Law 43/2014 ordinance 28/31.08.2011, and Law 43/11.04.2014 for the handling care, and protection of animals used for experimental purposes, the European Union Council Directive 98/58/EC concerning the protection of farmed animals and Directive 2010/63/EU on the protection of animals used for scientific purposes.

Birds, diets, and housing. The by-products used in this study were procured from an oil cold pressing producer (SC 2-EProd SRL) from Alexandria, Teleorman County, Romania. Before the usage of them in laying hens' diets, they had been shredded with an everyday MCU hammer mill ( $7.5 \mathrm{~kW}$ power), with $1 \mathrm{~mm}$ screen. Samples from each by-product (about $500 \mathrm{~g}$ ) were analysed for the proximate composition (dry matter, crude protein, crude fibre and ether extract), fatty acids content, total polyphenol content and antioxidant capacity (Table 5).

For the experiment, 120 Tetra SL LL laying hens, 50-week-old were used and assigned in a completely randomized design with three treatments (40 hens/group). A control diet (C) for laying hens based on corn and soybean meal with $2750 \mathrm{kcal} / \mathrm{kg}$ metabolizable energy and two supplemented diets, designed as follows: (T1) $9 \%$ rapeseed meal with 3\% grapeseed meal, and (T2) 9\% flaxseed meal with 3\% sea-buckthorn meal were individually prepared by mixing the control diet $(\mathrm{C})$ thoroughly with the designated supplements at the required incorporation levels as shown in Table 6. The dietary meals have been added to hens' diets as rich sources of PUFA and antioxidants (Table 6). Each group was allocated to one of the three following dietary treatments: C, T1 and T2. The laying hens were housed in an experimental hall equipped with Big Dutchman double-sided, 3-tier battery cages dimensioned according to the sanitary-veterinary norms regarding the protection standards for handling of laying hens. Each cage was equipped with individual nipple drinker. The metal feed trough was divided to ensure that the hens were not able to consume feed assigned to the adjoining replicate. The layers had free access to water and feed which was administrated once daily at 08:30. The environmental conditions were controlled with a Viper Touch computer: $20-22{ }^{\circ} \mathrm{C}$ temperature, $60-65 \%$ humidity, $2.5-3 \%$ ventilation and a photoperiod of $16 \mathrm{~h}$ light with $8 \mathrm{~h}$ darkness cycle. The experiment was conducted on 42 days from 50 to 56 weeks of age, with 2 weeks of accommodation period, from 48 to 50 weeks of age.

Proximate chemical composition analysis. The basic chemical composition analyses were determined on samples dried at $65^{\circ} \mathrm{C}$. Standardized methods were used to determine the nutrient concentration, performed according to the Regulation (CE) nr. 152/2009. Kjeldahl method was used for crude protein (CP) according to standard SR EN ISO 5983-2:2009 (Kjeltec 2300 Analyzer Unit, FOSS Analytical, Denmark). Crude fat (EE) was determined by extraction in organic solvents according to standard SR EN ISO 6492:2001 (Soxtec 2055-Foss 


\begin{tabular}{|c|c|c|c|}
\hline \multirow[b]{2}{*}{ Ingredients (\%) } & \multicolumn{3}{|c|}{ 50-56 weeks of age } \\
\hline & $\mathrm{C}$ & T1 & T2 \\
\hline Corn & 57.10 & 49.60 & 52.92 \\
\hline Soy meal & 21.24 & 15.00 & 16.69 \\
\hline Sunflower meal & 7.00 & 7.00 & 5.00 \\
\hline Rapeseed meal & 0.00 & 9.00 & 0.00 \\
\hline Grapeseed meal & 0.00 & 3.00 & 0.00 \\
\hline Sea-Buckthorn meal & 0.00 & 0.00 & 3.00 \\
\hline Flaxseed meal & 0.00 & 0.00 & 9.00 \\
\hline Sunflower vegetal oil & 2.02 & 4.08 & 0.00 \\
\hline L-Lysine-HCl & 0.06 & 0.08 & 0.14 \\
\hline DL-Methionine & 0.10 & 0.06 & 0.19 \\
\hline Choline & 0.05 & 0.05 & 0.05 \\
\hline Calcium carbonate & 9.91 & 9.63 & 10.4 \\
\hline Phosphate & 1.12 & 1.09 & 1.20 \\
\hline Mycotoxin inhibitor & 0.05 & 0.05 & 0.05 \\
\hline Sodium chloride & 0.35 & 0.36 & 0.36 \\
\hline Premix $^{\mathrm{a}}$ & 1.00 & 1.00 & 1.00 \\
\hline \begin{tabular}{|l|} 
Total ingredients \\
\end{tabular} & 100.00 & 100.00 & 100.00 \\
\hline \multicolumn{4}{|l|}{ Chemical composition of the diets } \\
\hline Metabolizable energy $(\mathrm{Kcal} / \mathrm{kg})$ & 2750.00 & 2750.00 & 2750.00 \\
\hline Crude protein (\%) & 16.50 & 16.50 & 16.50 \\
\hline Ether extract (\%) & 3.83 & 5.89 & 3.11 \\
\hline Crude fibre (\%) & 4.49 & 6.00 & 6.00 \\
\hline Palmitic acid (C16:0) (\%) & 10.17 & 9.19 & 13.53 \\
\hline Stearic acid (C18:0) (\%) & 2.56 & 2.62 & 2.38 \\
\hline Oleic acid (C18:1) (\%) & 28.68 & 29.00 & 24.48 \\
\hline a Linolenic acid (C18:3n3) (\%) & 0.78 & 1.22 & 15.41 \\
\hline Total PUFA (\%) & 57.77 & 58.61 & 58.72 \\
\hline n-6 PUFA (\%) & 56.20 & 54.78 & 44.84 \\
\hline \begin{tabular}{|l|} 
n-3 PUFA (\%) \\
\end{tabular} & 1.57 & 3.83 & 13.88 \\
\hline n-6/n-3 ratio (\%) & 35.87 & 14.19 & 2.94 \\
\hline Polyphenols (mg GAE/g) & 3.47 & 10.29 & 9.89 \\
\hline Antioxidant capacity (mM Trolox/g) & 8.60 & 14.41 & 16.62 \\
\hline Flavonoids ( $\mu$ g rutin/g) sample ( $\mu \mathrm{g} \mathrm{RE} / \mathrm{g}$ ) & 5.89 & 9.28 & 10.47 \\
\hline
\end{tabular}

Table 6. Ingredients and chemical composition of the diets. $C$ control diet, $T 1$ control diet with $9 \%$ rapeseed meal and 3\% grapeseed meal, T2 control diet with $9 \%$ flaxseed meal and 3\% sea-buckthorn meal, PUFA

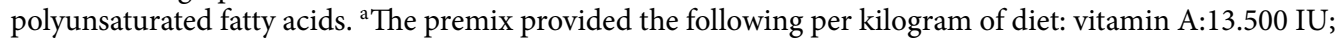
vitamin D3:3.000 IU; vitamin E:27 mg; vitamin K3: $2 \mathrm{mg}$; vitamin B1: 2 mg; vitamin B2: $4.8 \mathrm{mg}$; pantothenic acid: $14.85 \mathrm{mg}$; nicotinic acid: $27 \mathrm{mg}$; vitamin B6: $3 \mathrm{mg}$; vitamin B7: $0.04 \mathrm{mg}$; vitamin B9:1 mg; vitamin B12: $0.018 \mathrm{mg}$; vitamin C: $25 \mathrm{mg}$; manganese: $71.9 \mathrm{mg}$; iron: $60 \mathrm{mg}$; copper: $6 \mathrm{mg}$; zinc: $60 \mathrm{mg}$; cobalt: $0.5 \mathrm{mg}$; iodine: $1.14 \mathrm{mg}$; selenium: $0.18 \mathrm{mg}$.

Tecator, Sweden). For crude fiber (CF) the method with intermediary filtration was used according to standard SR EN ISO 6865:2002 (Fibertec 2010 System-Foss Tecator, Sweden).

Laying performance and egg quality traits. During the 42 experimental days (6 weeks), egg production (\%), average daily feed intake (g/day/layer), feed conversion ratio ( $\mathrm{g}$ feed/g egg mass), laying percentage (\%), and average egg weight (g/day), were monitored. Egg quality traits were determined as previously reported ${ }^{55}$. Briefly, by collecting 54 eggs (18 eggs/group) on last day of the trial, with homogenous weight and used to determine the physical quality parameters of the eggs: weight of the egg and its constituents (albumen, yolk, shell) with a Kern Precision Electronic Balance; Haugh Unit, an indicator of albumen quality was determined using an Egg Analyzer TM (ORKA Food Technology Ltd.), eggshell thickness, measured with an Egg Shell Thickness Gauge (Sanovo Engineering A/S, Denmark) and eggshell breaking strength, using an Egg Force Reader (Sanovo Engineering A/S, Denmark). The $\mathrm{pH}$ measurements (albumen and yolk) were performed with an INOLAB pHmeter (WTW, Weilheim, Germany). Yolk colour was determined by the Roche yolk colour fan (Hoffman-La Roche Ltd., Basel, Switzerland; colour scale from 15 dark orange, to 1, light pale). The fatty acid composition was determined from the pooled yolk samples, while the antioxidant capacity was determined separately from both yolk and white. 
Egg yolk fatty acids determination. The fatty acid (FA) profile from samples dried at $65^{\circ} \mathrm{C}$ was determined using the fatty acid methyl ester (FAME) gas chromatography according to ISO/TS 17764-2 (2008), as described by Turcu et al. ${ }^{12}$. The FA from the total lipid extracts were converted to their methyl esters by trans esterification in methanol containing 3\% concentrated sulfuric acid at $80^{\circ} \mathrm{C}$ for $4 \mathrm{~h}$. Methyl esters of FA were analysed in a Perkin Elmer-Clarus 500 chromatograph equipped with flame ionization detector (FID) and fitted with a BPX70 capillary column $(60 \mathrm{~m} \times 0.25 \mathrm{~mm}$ i.d., $0.25 \mu \mathrm{m}$ film thickness). The column temperature was programmed at $5{ }^{\circ} \mathrm{C} / \mathrm{min}$, until $180-220{ }^{\circ} \mathrm{C}$. The carrier gas was hydrogen $\left(35 \mathrm{~cm} / \mathrm{s}\right.$ linear velocity at $\left.180{ }^{\circ} \mathrm{C}\right)$ while the burning gas was air of analytical purity. The split ratio was 1:100. The injector and detector temperatures were $250{ }^{\circ} \mathrm{C}$ and $260^{\circ} \mathrm{C}$, respectively. FAME identification was done by comparison with retention times of the known standards. The results were expressed as mg of each FA per yolk. The average amount of each FA was used to calculate the sum of the total saturated (SFA), unsaturated (UFA), monounsaturated (MUFA) and polyunsaturated (PUFA) fatty acids.

Calculation of health lipid indices. The health profile of enriched egg yolk were calculated based on the proportions of particular FA and their groups, as follows: saturation indices (SI), atherogenic indices (AI), thrombogenic indices (TI), peroxidability indices (PI), ratio of hypocholesterolemic and hypercholesterolemic $(\mathrm{HH})$, hypercholesterolaemic saturated fatty acids (HFSA) oxidisability value (Cox), oxidative susceptibility (OS), desirable FA (DFA) and nutritive value indices (NVI) using the appropriate formulas ${ }^{1,6,36,38}$ :

$$
\begin{gathered}
\mathrm{SI}=(\mathrm{C} 14: 0+\mathrm{C} 16: 0+\mathrm{C} 18: 0) /(\mathrm{MUFA}+\mathrm{PUFA}) \\
\mathrm{AI}=(4 \times \mathrm{C} 14: 0+\mathrm{C} 16: 0+\mathrm{C} 18: 0) /(\mathrm{MUFA}+\mathrm{PUFA}) \\
\mathrm{TI}=(\mathrm{C} 14: 0+\mathrm{C} 16: 0+\mathrm{C} 18: 0) /(0.5 \times \mathrm{MUFA}+0.5 \times \mathrm{n} 6 \mathrm{PUFA}+3 \times \mathrm{n} 3 \mathrm{PUFA}+\mathrm{n} 3: \mathrm{n} 6) \\
\mathrm{PI}=(\% \text { monoenoic FA } \times 0.025)+(\% \text { dienoic FA } \times 1)+(\% \text { trienoic FA } \times 2) \\
+(\% \text { tetraenoic FA } \times 4)+(\% \text { pentaenoic FA } \times 6)+(\% \text { hexaenoic FA } \times 8) \\
\mathrm{HH}=(\mathrm{C} 18: 1 \mathrm{n} 9+\mathrm{C} 18: 2 \mathrm{n} 6+\mathrm{C} 20: 4 \mathrm{n} 6+\mathrm{C} 18: 3 \mathrm{n} 3+\mathrm{C} 20: 5 \mathrm{n} 3+\mathrm{C} 22: 5 \mathrm{n}-3 \\
+\mathrm{C} 22: 6 \mathrm{n} 6) /(\mathrm{C} 14: 0+\mathrm{C} 16: 0) \\
\mathrm{HSFA}=(\mathrm{C} 14: 0+\mathrm{C} 16: 0) \\
\mathrm{Cox}=(\mathrm{C} 18: 1+10.3 \times \mathrm{C} 18: 2+21.6 \times \mathrm{C} 18: 3) / 100 \\
\mathrm{OS}=\mathrm{MUFA}+45 \times \mathrm{C} 18: 2+100 \times \mathrm{C} 18: 3 \\
\mathrm{DFA}=(\mathrm{C} 18: 0+\mathrm{UFA}) \\
\mathrm{NVI}=(\mathrm{C} 18: 0+\mathrm{C} 18: 1) / \mathrm{C} 16: 0
\end{gathered}
$$

The peroxidability indices of the lipid, were calculated from the concentrations of specific FA and were quantified based on their abundance $(\%, w / w)$. The total monoenoic FA were given by the miristic, pentadecanoic, palmitic, heptadecanoic and stearic multiplied by 0.025 . The dienoic FA were given by linoleic and eicosadienoic multiplied by 1 . Trienoic fatty acids which are formed from all 18-carbon chain with three cis double links, linolenic $\gamma$, $\alpha$-linolenic, eicosatrienoic (C20:3n6) and eicosatrienoic (C20:3n3) multiplied by 2, while tetraenoic FA were calculated from arachidonic acid (C20:4n6) and docosatetraenoic (C22:4n6), which are formed from all 20 -carbon chain and four cis double links multiplied by 6 . For pentaenoic we determined only docosapentaenoic (C22:5n3) multiplied by 6 and for hexaenoic we determined docosahexaenoic acid (C22:6n 3$)$ multiplied by 8 .

Determination of antioxidant compounds. The total polyphenol concentration (TPC) and total antioxidant capacity (TAC) were determined as described by Olteanu et al.$^{56}$. Briefly, the TPC were determined spectrophotometrically in the methanolic extracts of samples, using a UV-Vis Thermo Scientific spectrophotometer, and the results were expressed in $\mathrm{mg}$ equivalents gallic acid/g (mg GAE/g sample). The TAC of the methanol extracts was determined by using the DPPH method, with an UV-Vis Analytik Jena Specord 250 Plus spectrophotometer with thermostatic carousel. The obtained results of TAC are expressed in Trolox equivalents/g sample (mM Trolox/g sample).

Statistical analysis. The statistical model was applied as reported previously ${ }^{55}$. One-way analysis of variance (ANOVA), using STATVIEW for WINDOWS (SAS, version 6.0) was carried out to determine the effect of diets on egg quality parameters, fatty acid composition, total polyphenols and antioxidant content in eggs. Significance between individual mean was identified using the Tukey's multiple range tests. Mean differences were considered significant at $p<0.05$. 
The Principal Component Analysis (PCA) was obtained from the corresponding function of MATLAB \& SIMULINK software package, used to reveal the correlation structure between the investigated parameters. PCA is a multivariate technique commonly adopted to reduce the dimensionality of data. By reducing the number of variables, the use of PCA allows an easier analysis and comparison of eggs quality characteristics and similarities between the groups. To obtain the PCA representation we considered centred and normalized version of the data. The first component (PC1) covered $75 \%$ of the global variance of the data while the second component (PC2) covered about $20 \%$ of the global variance.

\section{Data availability}

The datasets during and/or analysed during the current study are available from the corresponding authors on reasonable request.

Received: 25 June 2021; Accepted: 11 October 2021

Published online: 19 October 2021

\section{References}

1. Attia, Y. A., Al-Harthi, M. A., Korish, M. A. \& Shiboob, M. M. Fatty acid and cholesterol profiles and hypocholesterolemic atherogenic and thrombogenic indices of table eggs in the retail market. Lipids Health Disease. https://doi.org/10.1186/s12944-015-0133-Z (2015).

2. Gonzalez-Esquerra, R. \& Leeson, S. Alternatives for enrichment of eggs and chicken meat with omega-3 fatty acids. Can. J. Anim. Sci. 81(3), 295-305 (2001).

3. Ao, T. et al. Effects of supplementing microalgae in laying hen diets on productive performance fatty-acid profile and oxidative stability of eggs. J. Appl. Poultry Res. 24(3), 394-400. https://doi.org/10.3382/japr/pfv042 (2015).

4. Shahidi, F. \& Ambigaipalan, P. Omega-3 polyunsaturated fatty acids and their health benefits. Annu. Rev. Food Sci. Technol. 9, 345-381 (2018).

5. Hayat, Z., Cherian, G., Pasha, T. N., Khattak, F. M. \& Jabbar, M. A. Oxidative stability and lipid components of eggs from flax-fed hens: Effect of dietary antioxidants and storage. Poult. Sci. https://doi.org/10.3382/ps.2009-00256 (2010).

6. FAO/WHO (Food and Agricultural Organization of the United Nations and World Health Organization). Fats and Fatty Acids in Human Nutrition. Report of an Extract Consultation Vol. 91 (FAO Food Nutrition Papers, 2010).

7. Carrillo, S. et al. Potential use of seaweeds in the laying hen ration to improve the quality of n-3 fatty acid enriched eggs. in Nineteenth International Seaweed Symposium, 271-278. (Springer Dordrecht, 2008).

8. Fraeye, I. et al. Dietary enrichment of eggs with omega-3 fatty acids: A review. Food Res. Int. 48(2), 961-969 (2012).

9. Burdge, G. C., Tan, S. Y. \& Henry, C. J. Long-chain n-3 PUFA in vegetarian women: A metabolic perspective. J. Nutr. Sci. 6, e581 of 8. https://doi.org/10.1017/jns.2017.62 (2017).

10. Javed, A., Imran, M., Ahmad, N. \& Hussain, A. I. Fatty acids characterization and oxidative stability of spray dried designer egg powder. Lipids Health Dis. 17(1), 1-13 (2018).

11. Galobart, J., Barroeta, A. C., Baucells, M. D., Codony, R. \& Ternes, W. Effect of dietary supplementation with rosemary extract and $\alpha$-tocopheryl acetate on lipid oxidation in eggs enriched with $\omega 3$-fatty acids. Poult. Sci. 80(4), 460-467 (2001).

12. Turcu, R. P. et al. Grapeseed meal used as natural antioxidant in high fatty acid diets for hubbard broilers. Braz. J. Poult. Sci. https:// doi.org/10.1590/1806-9061-2018-0886 (2019).

13. Vlaicu, P. A. et al. Feeding quality of the meat from broilers fed with dietary food industry by-products (flaxseed rapeseeds and buckthorn meal grape pomace). Sci. Papers Series D Anim. Sci. 60, 123-130 (2017).

14. Zeb, A. Important therapeutic uses of sea buckthorn (Hippophae): A review. J. Biol. Sci. 4(5), 687-693 (2004).

15. Sepehr, A., Kashani, R. B., Esmaeili, M., Safari, O. \& Rombenso, A. Effects of extruded milled and whole flaxseed (Linum usitatissimum) on egg performance lipid components and fatty acids concentrations in yolk and blood and antioxidant system of commercial laying hens. Anim. Feed Sci. Technol. https://doi.org/10.1016/j.anifeedsci.2021.114877 (2021).

16. Gheisari, A. A., Ghayor, P., Eghbal-Saeid, S., Toghyani, M. \& Najafi, A. A. Effect of different dietary levels of rapeseed meal on reproductive performance of Iranian indigenous breeder hens. Asian J. Anim. Vet. Adv. 6(1), 62-70 (2011).

17. Halle, I. Laying performance in hens of two breeds testing soybean meal or rapeseed meal plus peas as protein feed. Landbauforsch Apploed Agric. For. Res. 67, 25-32 (2017).

18. Ceylan, N., Ciftçi, I., Mizrak, C., Kahraman, Z. \& Efil, H. Influence of different dietary oil sources on performance and fatty acid profile of egg yolk in laying hens. J. Anim. Feed Sci. 20(1), 71-83 (2011).

19. Grashorn, M. Feed additives for influencing chicken meat and egg yolk color. in Handbook on Natural Pigments in Food and Beverages, Woodhead Publishing, 283-302 (2016).

20. Momani, S. M., Al-Beitawi, N. A., Bláha, J. \& Mahmoud, Z. The effect of sea buckthorn (Hippophae rhamnoides L.) fruit residues on performance and egg quality of laying hens. J. Appl. Anim. Res. https://doi.org/10.1080/09712119.2017.1324456 (2018).

21. Burdge, G. C. \& Calder, P. C. Introduction to fatty acids and lipids. Intravenous Lipid Emulsions. 112, 1-16 (2015).

22. Turchini, G. M., Francis, D. S. \& De Silva, S. S. A whole body in vivo fatty acid balance method to quantify PUFA metabolism (desaturation elongation and beta-oxidation). Lipids https://doi.org/10.1007/s11745-008-3213-2 (2007).

23. Omidi, M., Rahimi, S. \& Torshizi, M. A. K. Modification of egg yolk fatty acids profile by using different oil sources. Vet. Res. Forum. 6(2), 137 (2015) (Faculty of Veterinary Medicine Urmia University Urmia Iran).

24. Halle, I. \& Schöne, F. Influence of rapeseed cake linseed cake and hemp seed cake on laying performance of hens and fatty acid composition of egg yolk. J. Verbr. Lebensm. 8(3), 185-193 (2013).

25. Rowghani, E., Arab, M., Nazifi, S. \& Bakhtiari, Z. Effect of canola oil on cholesterol and fatty acid composition of egg-yolk of laying hens. Int. J. Poul. Sci. 6(2), 111-114 (2007).

26. Baucells, M. D., Crespo, N., Barroeta, A. C., Lopez-Ferrer, S. \& Grashorn, A. M. Incorporation of different polyunsaturated fatty acids into eggs. Poul. Sci. 79(1), 51-59 (2000).

27. Saini, R. K. \& Keum, Y. S. Omega-3 and omega-6 polyunsaturated fatty acids: Dietary sources metabolism and significance-A review. Life Sci. https://doi.org/10.1016/j.lfs.2018.04.049 (2018).

28. Imran, M. et al. Production of Bio-omega-3 eggs through the supplementation of extruded flaxseed meal in hen diet. Lipids Health Dis. https://doi.org/10.1186/s12944-015-0127-x (2015).

29. Bean, L. D. \& Leeson, S. Long-term effects of feeding flaxseed on performance and egg fatty acid composition of brown and white hens. Poult. Sci. 82(3), 388-394 (2003).

30. Sparks, N. H. C. The hen's egg-Is its role in human nutrition changing?. Worlds Poult. Sci. J. 62(2), 308-315 (2006).

31. Cooke, H. W. Fatty acid desaturation and chain elongation in eucaryocytes. In Biochemistry of Lipids Lipoproteins and Membranes (eds Vance, D. E. \& Vance, J.) 141-169 (Elsevier, 1991).

32. Attia, Y. A., Al-Harthi, M. A., Korish, M. A. \& Shiboob, M. M. Fatty acid and cholesterol profiles hypocholesterolemic atherogenic and thrombogenic indices of broiler meat in the retail market. Lipids Health Dis. 16(1), 1-11 (2017). 
33. Liu, B., Jiang, J., Yu, D., Lin, G. \& Xiong, Y. L. Effects of supplementation of microalgae (Aurantiochytrium sp.) to laying hen diets on fatty acid content health lipid indices oxidative stability and quality attributes of meat. Foods. https://doi.org/10.3390/foods 9091271 (2020).

34. Mapiye, C. et al. Fatty acid composition of beef from Nguni steers supplemented with Acacia karroo leaf-meal. J. Food Compos. Anal. 24(4-5), 523-528 (2011).

35. Ghaemi, A. et al. How much weight loss is effective on nonalcoholic fatty liver disease?. Hepat. Mon. https://doi.org/10.5812/hepat mon.15227 (2013).

36. Omri, B. et al. Egg yolk antioxidants profiles: Effect of diet supplementation with linseeds and tomato-red pepper mixture before and after storage. Foods. https://doi.org/10.3390/foods8080320 (2019).

37. Tonial, I. B. et al. Quantification of essential fatty acids and assessment of the nutritional quality indexes of lipids in tilapia alevins and juvenile tilapia fish (Oreochromis niloticus). J. Food Res. 3(3), 105-114. https://doi.org/10.5539/jfr.v3n3p105 (2014).

38. Batkowska, J., Drabik, K., Brodacki, A., Czech, A. \& Adamczuk, A. Fatty acids profile cholesterol level and quality of table eggs from hens fed with the addition of linseed and soybean oil. Food Chem. https://doi.org/10.1016/j.foodchem.2020.127612 (2021).

39. Kralik, G., Kralik, Z., Grčević, M. \& Hanžek, D. Qualitative characteristics of fatty acid profile in fresh and boiled n-3 PUFA enriched eggs. J. Central Eur. Agric. 20(3), 802-808 (2019).

40. Carlsen, M. H. et al. The total antioxidant content of more than 3100 foods, beverages, spices, herbs and supplements used worldwide. Nutr. J. 9(1), 1-11 (2010).

41. Swapna, L. A. et al. Antioxidants and their implication in oral health and general health. Int. J. Case Rep. Images. 5(4), 258-263 (2014).

42. Sameh, S., Al-Sayed, E., Labib, R. M. \& Singab, A. N. Genus spondias: A phytochemical and pharmacological review. EvidenceBased Complem. Alternative Med. https://doi.org/10.1155/2018/5382904 (2018).

43. Baiano, A. et al. Changes in phenolic content and antioxidant activity of Italian extra-virgin olive oils during storage. J. Food Sci. https://doi.org/10.1111/j.1750-3841.2009.01072.x (2009).

44. Vlaicu, P. A., Untea, A. E., Panaite, T. D. \& Turcu, R. P. Effect of dietary orange and grapefruit peel on growth performance health status meat quality and intestinal microflora of broiler chickens. Ital. J. Anim. Sci. https://doi.org/10.1080/1828051X.2020.18455 $76(2020)$.

45. Karakaya, S. N., El, A. A. \& Taş, S. Antioxidant activity of some foods containing phenolic compounds. Int. J. Food Sci. Nutr. https:// doi.org/10.1080/09637480020027000-6-6 (2001).

46. Brenes, A. et al. Effect grape seed extract on growth performance protein and polyphenol digestibilities and antioxidant activity in chickens. Span. J. Agric. Res. 2, 326-333 (2010).

47. Dvořák, P., Suchý, P., Straková, E. \& Doležalová, J. The effect of a diet supplemented with sea-buckthorn pomace on the colour and viscosity of the egg yolk. Acta Vet. Brno 86(3), 303-308 (2017).

48. Surai, P.F., Papazyan, T.T., Sparks, N.H., Speake, B.K. Simultaneous enrichment of eggs with PUFAs and antioxidants. in Wild-Type Food in Health Promotion and Disease Prevention, Humana Press, 139-153 (2008).

49. World Health Organization. Diet Nutrition and the Prevention of Chronic Diseases: Report of a Joint WHO/FAO Expert Consultation 916 (World Health Organization, 2003).

50. Scalbert, A., Manach, C., Morand, C., Rémésy, C. \& Jiménez, L. Dietary polyphenols and the prevention of diseases. Crit. Rev. Food Sci. Nutr. 45(4), 287-306. https://doi.org/10.1080/1040869059096 (2005).

51. Williamson, G. \& Manach, C. Bioavailability and bioefficacy of polyphenols in humans. II. Review of 93 intervention studies. Am. J. Clin. Nutr. https://doi.org/10.1093/ajen/81.1.243S (2005).

52. Vita, J. A. Polyphenols and cardiovascular disease: Effects on endothelial and platelet function. Am. J. Clin. Nutr. https://doi.org/ 10.1093/ajcn/81.1.292S (2005)

53. Sies, H., Schewe, T., Heiss, C. \& Kelm, M. Cocoa polyphenols and inflammatory mediators. Am. J. Clin. Nutr. https://doi.org/10. 1093/ajen/81.1.304S (2005).

54. Arts, I. C. \& Hollman, P. C. Polyphenols and disease risk in epidemiologic studies. Am. J. Clin. Nutr. https://doi.org/10.1093/ajen/ 81.1.317S (2005).

55. Vlaicu, P. A. \& Panaite, T. D. Effect of dietary pumpkin (Cucurbita moschata) seed meal on layer performance and egg quality characteristics. Anim. Biosci. https://doi.org/10.5713/ab.21.0044.PMID:34293842 (2021).

56. Olteanu, M. et al. Quality of the eggs obtained from hens fed diet formulations rich in polyunsaturated fatty acids and with grape seeds meal as antioxidant. Archiva Zootechnica. 20(1), 37-49 (2017).

\section{Acknowledgements}

This paper was done within project financed through Ministry of Agriculture and Rural Development Program ADER 9.1.2./14.10.2019 and by Romanian Ministry of Research and Digitalization, grant number PN 1909-0102.

\section{Author contributions}

P.A.V. conceptualization, reviewed the literature, conducted statistical analyses, drafted and edited the manuscript. T.D.P. conceived the experiment, visualization and funding acquisition. R.P.T. collected the data and conducted chemical analysis, P.A.V.; T.D.P. and R.P.T. analysed the results. All authors read and approved the final manuscript.

\section{Competing interests}

The authors declare no competing interests.

\section{Additional information}

Correspondence and requests for materials should be addressed to P.A.V.

Reprints and permissions information is available at www.nature.com/reprints.

Publisher's note Springer Nature remains neutral with regard to jurisdictional claims in published maps and institutional affiliations. 
(c) (i) Open Access This article is licensed under a Creative Commons Attribution 4.0 International cc) License, which permits use, sharing, adaptation, distribution and reproduction in any medium or format, as long as you give appropriate credit to the original author(s) and the source, provide a link to the Creative Commons licence, and indicate if changes were made. The images or other third party material in this article are included in the article's Creative Commons licence, unless indicated otherwise in a credit line to the material. If material is not included in the article's Creative Commons licence and your intended use is not permitted by statutory regulation or exceeds the permitted use, you will need to obtain permission directly from the copyright holder. To view a copy of this licence, visit http://creativecommons.org/licenses/by/4.0/.

(C) The Author(s) 2021 